\title{
Educational and retraining programs in the International Laser Center of Moscow State University
}

\author{
V. Makarov, S. Shlenov
}

V. A. Makarov, S. A. Shlenov, "Educational and retraining programs in the International Laser Center of Moscow State University," Proc. SPIE 9664, Ninth International Topical Meeting on Education and Training in Optics and Photonics, 96640 S (24 October 2005); doi: 10.1117/12.2207694

SPIE Event: Ninth International Topical Meeting on Education and Training in Optics and Photonics, 2005, Marseille, France 


\title{
Ref ETOP036
}

\section{Educational and Retraining Programs in the International Laser Center of Moscow State University}

\author{
V.A. Makarov, S.A. Shlenov
}

International Laser Center of Lomonosov Moscow State University, Moscow, Russia

\begin{abstract}
We present educational programs on nonlinear optics and laser physics in the ILC MSU. These programs are aimed on both full-time students of physics faculty and students of retraining courses. As a part of life-long learning we offer different types of programs ranging from short courses to one-year long retraining programs. These programs include lecture courses, practical work in the training laboratories, and graduate research work in the scientific labs under a supervision of an expert. Special attention will be paid to new tendencies in the educational activities at the ILC MSU: developing and using multimedia courses, short-range practical courses in adjacent fields, constantly developing university teaching laboratory on laser physics and optics.
\end{abstract}

\section{Keywords}

University education, continuing education, retraining programs, teaching laboratory, laser physics, photonics, nonlinear optics, nonlinear spectroscopy, laser diagnostics, ultrastrong light fields, lasers and laser systems, physics of surface and nanostructures, laser optoacoustics, laser biophysics and biomedicine, adaptive optics, quantum statistical optics, physics of quantum information, multimedia lecture notes, automation systems, certificate exam.

\section{Summary}

International Laser Center of Lomonosov Moscow State University (ILC MSU) governs the activities in laser physics, photonics and nonlinear optics within the MSU. ILC MSU provides training of students in well-equipped laser laboratories, conducts the continuing education and retraining programs, offers to scientists the necessary tools for the laser research.

Educational programs of ILC MSU are aimed on both full-time students of physics faculty and students of retraining courses. Each year more than 30 senior students come to the laser center to fulfill course projects and final diploma work. The students can be taught at their discretion in dozen experimental laboratories and several theoretical groups. The biggest laboratory in the ILC MSU is the recently established Center for Laser Femtotechnologies and Ultrastrong Light Fields (multiuser facility). The Center is equipped with a terawatt femtosecond titanium-sapphire laser system (pulse duration $70 \mathrm{fs}$; wavelength $800 \mathrm{~nm}$; pulse energy $40 \mathrm{~mJ}$; pulse repetition rate $10 \mathrm{~Hz}$ ). Among others are the laboratories of Adaptive optics, Photonics and nonlinear spectroscopy, Laser optoacoustics, Time-domain spectroscopy of molecular and atomic gases, Ultrafast processes in biology. In parallel with working in a lab the students attend lecture courses. Each laboratory offer one or several specialized courses. For instance, professors and research staff from adaptive optics laboratory deliver lectures on modern problems of adaptive optics and optical data processing. 
The students of physics faculty are with an ILC scientific laboratory from the fourth year of study through the presentation final diploma work after five and a half year of study in the university. They choose chair and laboratory in the third year of study though it is also possible to change scientific adviser and laboratory later on. Most of the students get so called Specialist's degree. However nowadays it is also possible to have Master's degree after 4+2 years of study.

The postgraduate students come to the ILC MSU to carry out investigations and write their Ph.D. thesis. The main areas of research are the following: nonlinear optics and photonics, nonlinear spectroscopy and laser diagnostics, ultrastrong light fields and its applications, lasers and laser systems, physics of surface and nanostructures, laser optoacoustics, laser biophysics and biomedicine, adaptive optics and optics of random heterogeneous media, x-ray optics, quantum statistical optics, physics of quantum information. Dozen of experimental laboratories and several theoretical groups are at their service.

As a part of life-long learning we offer different types of programs ranging from short courses to one-year long retraining programs. Probation at the ILC laboratories lasts from one to ten months in accordance with individual plans. Two one-year retraining programs "Laser physics and technology" and "Nonlinear optics and laser optoacoustics" are intended first of all for the specialists in different fields who want to apply lasers and nonlinear optics techniques in their work and research. These programs include lecture courses (some obligatory, some optional), practical work in the training laboratories, and graduate research work in the scientific labs under a supervision of an expert. The graduates are awarded state diploma in professional retraining.

The ILC MSU is the organizer of the Laser Graduate School. Each session of the School lasts from a few days up to two weeks and consists of short courses (2 to 8 hours each) delivered by top experts from the leading laboratories and universities all around the world. Each course is devoted to one of the urgent topics of modern laser physics and nonlinear optics and provides an introduction to the subject, a brief history of research in this area, the main achievements and current state of the art in the field, as well as the outlook and some key references. The short courses program activity provides an excellent opportunity for the students (graduate students, young scientists, etc.) to "get in touch" with the Science not just reading the papers in scientific journals, but attending the instructor's courses, talking to them, asking questions. For students of Moscow University, these short courses are part of their regular lecture courses.

Among new tendencies in the educational activities at the ILC MSU we could mark out developing and creating multimedia lecture notes [1]. The baseline of these notes is a sound track of recorded lecturer's presentation for live audience. Then the video frames with formulae, figures, comments etc. are added by means of Macromedia Flash software package. As a result the multimedia notes keep live auditorium sounding, preserve personal lecturer peculiarity and produce an effect of virtual presence on real lecture. On the other hand, after being computer processed they have easily readable writings, incorporate pictures and animation, have friendly interface. The multimedia lecture notes are used for individual training and preview of the lecture topics.

Much attention is given at ILC MSU to maintain and develop the classical practicum with laser and nonlinear optics setups, which are used for learning how to plan and carry out an 
optics or laser experiment. Teaching laboratory is permanently updated with modern setups, which just a few years ago could be found only in a scientific laboratory. We try to smooth the difference between learning things inside educational environment and working in a real lab. For instance, the ILC's teaching laboratory has Ytterbium doped fiber laser, and corresponding laboratory work familiarizes students with a single mode fiber optic laser with diode pumping. The students make measurements of output parameters of radiation in continuous wave regime. They study the optical scheme of the laser, the properties of distributed Bragg mirrors using semi classical approach. The problem of conversion efficiency of the laser is discussed when a student fulfills this work.

Note that a modern experiment in optics cannot be practically done without advanced system of automation. Computer assisted adjustment of optical elements; control of the experiment, data acquisition have become usual practice.

To improve the quality of education and to make it more flexible a new laboratory "Modern automation systems for scientific researches" was founded at ILC MSU in autumn 2004. The laboratory are equipped with 10 test-stands, 20 sets of National Instruments equipments (data acquisition and GPIB interface boards, RS-232 and GPIB devices), machine vision systems, and full pack of LabVIEW software. Since 2005 the laboratory has a status of authorized National Instruments educational Center. Students study LabVIEW programming using authorized programs and courses of National Instruments Corporation. The Center offers training to pass international certificate exam National Instruments Certified LabVIEW Associate Developer. Students of retraining program can choose courses of different complexity: from getting started courses of LabVIEW programming for beginners to advanced courses for highskilled professionals. The retraining program consists of blocks of courses. Each course is very compact in time (from 20 up to 72 hours). At the end of the course each student presents selfmade work on experiment automation. Everyone who passed a test is rewarded with a state certificate of retraining.

Thus, International Laser Center of Lomonosov Moscow State University offer facilities, including modern experimental setups, for students and postgraduate students to prepare diploma and Ph.D. thesis in the field of laser physics and nonlinear optics. We develop both classical practicum and new virtual technologies for automation systems. Several programs are intended for continuing education and retraining courses.

\section{References}

1. V.A. Makarov, V.O. Militsyn, S.A. Shlenov, V.V. Shuvalov, D.N. Yanyshev. Compilation of Multi-Media Lecture Notes on Laser Physics Using Flash Technologies. // Physics in Higher Education (Rus). V. 11, No. 2, p. 15-26 (2005). 